\title{
Predicting the Health-related Quality of Life in Patients Following Traumatic Brain Injury
}

\author{
Thara Tunthanathip, MD, PhD ${ }^{1}$ Thakul Oearsakul, MD ${ }^{1}$ Pimwara Tanvejsilp, $\mathrm{PhD}^{2}$ \\ Sakchai Sae-heng, MD ${ }^{1}$ Anukoon Kaewborisutsakul, MD ${ }^{1} \quad$ Suphavadee Madteng, RN ${ }^{1} \quad$ Srirat Inkate, $\mathrm{RN}^{1}$ \\ ${ }^{1}$ Division of Neurosurgery, Department of Surgery, Faculty of \\ Medicine, Prince of Songkla University, HatYai, Songkhla, Thailand \\ 2 Department of Pharmacy Administration, Faculty of Pharmaceutical \\ Sciences, Prince of Songkla University, HatYai, Songkhla, Thailand \\ Address for correspondence Thara Tunthanathip, MD, PhD, Division \\ of Neurosurgery, Department of Surgery, Faculty of Medicine, Prince \\ of Songkla University, Hat Yai, Songkhla, Thailand 90110 \\ (e-mail: tsus4@hotmail.com).
}

Surg J (NY) 2021;7:e100-e110.

\section{Abstract \\ Keywords \\ - traumatic brain injury \\ - heath-related quality of life \\ - EQ-5D-5L}

Background Traumatic brain injury (TBI) commonly causes death and disability that can result in productivity loss and economic burden. The health-related quality of life (HRQoL) has been measured in patients suffering from TBI, both in clinical and socioeconomic perspectives. The study aimed to assess the HRQoL in patients following TBI using the European quality of life measure-5 domain-5 level (EQ-5D-5L) questionnaire and develop models for predicting the EQ-5D-5L index score in patients with TBI.

Method A cross-sectional study was performed with $193 \mathrm{TBI}$ patients who had completed the EQ-5D-5L questionnaire. The clinical characteristics, Glasgow coma scale (GCS) score, treatment, and Glasgow outcome scale (GOS) were collected. The total data was divided into training data $(80 \%)$ and testing data $(20 \%)$; hence, the factors affecting the EQ-5D-5L index scores were used to develop the predictive model with linear and nonlinear regression. The performances of the predictive models were estimated with the adjusted coefficient of determination $\left(R^{2}\right)$ and the root mean square error (RMSE).

Results A good recovery was found at $96.4 \%$, while $2.1 \%$ displayed an unfavorable outcome. Moreover, the mean EQ-5D-5L index scores were 0.91558 (standard deviation [SD] 1.09639). GCS score, pupillary light reflex, surgery, and GOS score significantly correlated with the HRQoL scores. The multiple linear regression model had a high adjusted $R^{2}$ of 0.6971 and a low RMSE of 0.06701 , while the polynomial regression developed a nonlinear model that had the highest adjusted $R^{2}$ of 0.6843 and the lowest RMSE of 0.06748 .

Conclusions A strong positive correlation between the physician-based outcome as GOS and HRQoL was observed. Furthermore, both the linear and nonlinear regression models were acceptable approaches to predict the HRQoL of patients after TBI. There would be limitations for estimating the HRQoL in unconscious or intubated patients. The HRQoL obtained from the predictive models would be an alternative method to resolve this problem. received

September 6, 2020 accepted after revision November 12, 2020
DOI https://doi.org/ $10.1055 / \mathrm{s}-0041-1726426$ ISSN 2378-5128.

\section{(c) 2021. The Author(s)}

This is an open access article published by Thieme under the terms of the Creative Commons Attribution License, permitting unrestricted use, distribution, and reproduction so long as the original work is properly cited. (https://creativecommons.org/licenses/by/4.0/)

Thieme Medical Publishers, Inc., 333 Seventh Avenue, 18th Floor, New York, NY 10001, USA 
The Center for Disease Control and Prevention (CDC) has proposed that traumatic brain injury (TBI) is a major public health problem, which can cause morbidity and mortality for adolescents and middle-aged persons in Thailand. ${ }^{1-3}$ To be specific, road traffic accidents (RTA) have been frequently the main means of TBI. Mortality from RTA has been reported to be 22,487 to 26,312 persons per year. ${ }^{4}$ Major disability following TBI in patients ranged from 0.3 to $1.7 \%$, while the mortality rate was reported as 3.2 to $5.2 \%$ of all TBIs. ${ }^{5-7}$ Fulkerson et al studied severe TBI with a Glasgow coma scale (GCS) score of 3 and 4 and found that $56.7 \%$ died within the first year following TBI. ${ }^{8}$ Furthermore, the $\mathrm{CDC}$ reported that severe TBI had lifetime economic costs, which were direct and indirect medical costs and were estimated to be approximately US $\$ 76.5$ billion in $2010 .{ }^{9}$ Hence, the evaluation of the economic burden of TBI should be conducted in all aspects. $^{10-12}$

Consequently, both qualitative and quantitative human resource losses from posttraumatic long-term sequelae and death have been recognized. The health-related quality of life (HRQoL) has been recognized as the World Health Organization's (WHO) basic principle. HRQoL refers to the individual's perception of well-being in the physical, mental, and social domains. $^{13}$

The HRQoL is considered as one of the health outcome indicators, and various HRQoL measurement tools have been used to estimate TBI, such as the quality of life after brain injury overall scale (QOLIBRI-OS) ${ }^{14,15}$ and the traumatic brain injury caregiver quality of life (TBI-CareQOL). ${ }^{16}$ von Steinbuechel et al measured the HRQoL among 795 patients with TBI using QOLIBRI-OS and found that the extended Glasgow outcome scale (GOS-E) was associated with HRQoL, ${ }^{14}$ while Born et al used this questionnaire and reported that severe head injury and injured extremities were associated with a poorer HRQoL. ${ }^{15}$ Moreover, Steadman-Pare et al explored the factors associated with HRQoL by using the self-rated quality of life scale. They found that gender, participation in work and leisure, and emotional support were significantly associated with the HRQoL. ${ }^{17}$

Currently, no consensus has been reached to measure HRQoL in TBI. The European quality of life measure-5 domain-5 level (EQ-5D-5L) questionnaire is one of the most widely used generic and preference-based instruments to estimate HRQoL in many countries that provide health norms. ${ }^{18-20}$ Moreover, this instrument has been used for HRQoL measurement in patients with various diseases such as cancer, degenerative diseases, or metabolic diseases. ${ }^{21-24}$

Prior research has studied the health status using the EQ5D-5L questionnaire in TBI. In detail, Voormolen et al studied the HRQoL measured by the EQ-5D-5L questionnaire and the Rivermead postconcussion symptoms questionnaire which compared between patients with and without postconcussion syndrome (PCS) following TBI. The results demonstrated that mean EQ-5D-5L index scores in the PCS group were significantly lower than the non-PCS group. ${ }^{25}$ Ward et al conducted a systematic review and mapping study to build a predictive model from age, gender, comorbidity, extracranial injury, and the Glasgow outcome scale (GOS) for predicting the HRQoL as the EQ-5D-5L index score. ${ }^{26}$ However, there is a lack of evidence of the HRQoL assessment using the EQ-5D$5 \mathrm{~L}$ being directly applied to TBI patients from the literature review. Because of this gap, the present study aimed to assess the HRQoL in patients following TBI using the EQ-5D-5L and develop a model for predicting the EQ-5D-5L index score in patients with TBI.

\section{Methods}

\section{Study Designs and Study Population}

A cross-sectional study was performed to assess the HRQoL using the EQ-5D-5L after the research ethics committee approval (REC.61-116-10-1). The study population included TBI patients who were 18 years or older between October 2018 to March 2020 and admitted to a trauma center in southern Thailand. However, patients were excluded for the following reasons: (1) patients died within 48 hours; (2) patients were not able to perform the EQ-5D-5L by themselves and had no caregiver to complete the questionnaire; (3) foreign patients who were non-Thai or non-English speaking.

Eligible subjects had the purpose and the study protocol explained to them, and all patients who agreed with the study protocol signed the informed consent. Hence, the EQ5D-5L questionnaire in English or Thai language ${ }^{26-28}$ was completed by self-reporting or proxy reporting before the patients were discharged from hospital. Additionally, electronic medical records were collected such as the clinical characteristics, treatment, and functional outcomes. After resuscitation, the GCS scores were categorized into mild TBI (GCS score 13-15), moderate TBI (GCS score 9-12), and severe TBI (GCS score 3-8). ${ }^{4}$ The functional outcome of the present study was assessed using the GOS when the patients were discharged from hospital. The author used the following GOS categories: $1=$ death, $2=$ a vegetative state, $3=$ severe disability, $4=$ moderate disability, and $5=\mathrm{a}$ good recovery. ${ }^{29-31}$

\section{Health-related Quality of Life (HRQoL)}

The EQ-5D-5L is an HRQoL questionnaire that was introduced by the EuroQol Research Foundation (EuroQoL). The author was allowed to use the questionnaire by the EuroQoL, which comprised five dimensions which are as follows: mobility, self-care, usual activities, pain/discomfort, and anxiety/depression. Each dimension consisted of five levels of response (no problems, slight problems, moderate problems, severe problems, and extreme problems). ${ }^{27}$ The EQ$5 \mathrm{D}-5 \mathrm{~L}$ was completed by the patients or caregivers; consequently, their responses were converted to scores based on the method of Pattanaphesaj et al. ${ }^{28,32}$ Also, the direct assessment of the HRQoL was performed simultaneously by a visual analogue scale (VAS); however, the EQ-5D-5L index scores were mainly analyzed in the present study.

\section{Statistical Analysis}

The clinical characteristics were calculated from the descriptive data. The categorical variables were described in 
e102 Predicting the Health-related Quality of Life in Patients Following Traumatic Brain Injury Tunthanathip et al.

percentages, while the mean with standard deviation (SD) or median with the interquartile range (IQR) was used for describing the continuous variables.

The continuous variables were compared with the MannWhitney $U$ test because of the non-Gaussian distribution, while the GCS and GOS were also compared between the subgroups by one-way analysis of variance (ANOVA) test. A scatter plot was performed for visualizing the relationship between the EQ-5D-5L and independent variables. Spearman's correlation was performed, and multicollinearity was explored when the correlation coefficient was more than 0.8 . The variance inflation factor (VIF) and tolerance were used to estimate the multicollinearity. A VIF of more than 10 and a tolerance of less than 0.2 were defined as multicollinearity. ${ }^{33,34}$

Eighty percent of the total data was used to develop the predictive model, while the remaining $20 \%$ was used to test the model's prediction performance. Therefore, linear regression was performed to identify the variables associated with the EQ-5D-5L index score using linear regression. A threshold $p$ value of less than 0.1 was used to estimate the candidate variables for selection in the final model. Multiple regression analyses were also performed using the backward elimination procedure, and statistical significance was observed with a $p$ value of less than 0.05 . Therefore, a model of the nonlinear regression was achieved compared with the model of linear regression. Moreover, the adjusted coefficient of determination $\left(R^{2}\right)$ referred to the predictive model's level of performance by explaining the EQ-5D-5L, while the value of the root mean square error (RMSE) was the performance of the model's prediction. The statistical analysis was performed using the R version 3.6.2 software ( $R$ Foundation, Vienna, Austria).

\section{Results}

Of the 729 TBI patients enrolled in the study, 193 patients consented and completed the questionnaire. Additionally, four patients were excluded because they were foreign patients who could not communicate in Thai or English languages. The mean age was 39.2 (SD 16.5), with a range of 18 to 78 years, while the median age was 36 (IQR 29). More than two-thirds of the group were male, with road traffic accidents (RTA) being the major cause of TBI (67.9\%). After resuscitation, $92.7 \%$ of the cases had mild TBI, while $7.2 \%$ had moderate-to-severe TBI. Almost all of the cohort had normal pupillary light reflex in both eyes. Mortality was not found in the present study, while $96.4 \%$ of all participants had a good recovery. Furthermore, the mean EQ-5D-5L index scores were 0.91558 (SD 1.09639), while the mean VAS score was 94.08 (SD 9.71). The baseline characteristics are presented in -Table 1.

- Table 2 shows the mean and median of the EQ-5D-5L index value according to each variable after dividing the data. As a result, the GCS, surgery, pupillary light reflex, and GOS were significantly different from the mean EQ-5D-5L index scores. Additionally, the EQ-5D-5L index score was positively correlated to the GCS score $(r=0.70 ; p<0.001)$ and GOS
Table 1 Demographic data of pediatric TBI $(n=193)$

\begin{tabular}{|c|c|}
\hline Factor & $n(\%)$ \\
\hline \multicolumn{2}{|l|}{ Age group-year } \\
\hline$<40$ & $102(52.8)$ \\
\hline$\geq 40$ & $91(47.2)$ \\
\hline Mean age- months (SD) & $39.2(16.5)$ \\
\hline Median age- months (IQR) & $36(29)$ \\
\hline \multicolumn{2}{|l|}{ Gender } \\
\hline Male & $120(62.2)$ \\
\hline Female & $73(37.8)$ \\
\hline \multicolumn{2}{|l|}{ Mechanism of injury } \\
\hline Road traffic injury & $131(67.9)$ \\
\hline Nonroad traffic injury & $62(32.1)$ \\
\hline \multicolumn{2}{|l|}{ Loss of consciousness } \\
\hline No & $152(78.8)$ \\
\hline Yes & $41(21.2)$ \\
\hline \multicolumn{2}{|l|}{ Amnesia } \\
\hline No & $164(85.0)$ \\
\hline Yes & $29(15.0)$ \\
\hline \multicolumn{2}{|l|}{ Vomiting } \\
\hline No & $153(79.3)$ \\
\hline Yes & $40(20.7)$ \\
\hline \multicolumn{2}{|l|}{ Scalp hematoma/laceration } \\
\hline No & $83(43.0)$ \\
\hline Yes & $110(57.0)$ \\
\hline \multicolumn{2}{|l|}{ Bleeding per ear/nose } \\
\hline No & $186(96.4)$ \\
\hline Yes & $7(3.6)$ \\
\hline \multicolumn{2}{|l|}{ Hypotension episode } \\
\hline No & $190(98.4)$ \\
\hline Yes & $3(1.6)$ \\
\hline \multicolumn{2}{|l|}{ Seizure } \\
\hline No & $190(98.4)$ \\
\hline Yes & $3(1.6)$ \\
\hline \multicolumn{2}{|l|}{ GCS score } \\
\hline $13-15$ & $179(92.7)$ \\
\hline $9-12$ & $7(3.6)$ \\
\hline $3-8$ & $7(3.6)$ \\
\hline Mean GCS & $14.46(1.69)$ \\
\hline \multicolumn{2}{|l|}{ Pupillary light reflex } \\
\hline Nonreact pupils & $6(3.1)$ \\
\hline React pupils & $187(96.9)$ \\
\hline \multicolumn{2}{|l|}{ Surgery } \\
\hline No & $177(91.7)$ \\
\hline Decompressive craniectomy & $5(2.6)$ \\
\hline
\end{tabular}


Predicting the Health-related Quality of Life in Patients Following Traumatic Brain Injury Tunthanathip et al. e103

Table 1 (Continued)

\begin{tabular}{|l|l|}
\hline Factor & $\boldsymbol{n}(\%)$ \\
\hline Craniotomy with clot removal & $11(5.7)$ \\
\hline GOS & 0 \\
\hline Death & $1(0.5)$ \\
\hline Vegetative state & $3(1.6)$ \\
\hline Severe disability & $3(1.6)$ \\
\hline Moderate disability & $186(96.4)$ \\
\hline Good recovery & $94.08(9.71)$ \\
\hline Mean VAS scores & $98(90,100)$ \\
\hline Median VAS scores & $0.91558(1.09639)$ \\
\hline Mean EQ-5D-5L index scores & $0.93200(0.068)$ \\
\hline Median EQ-5D-5L index scores
\end{tabular}

Abbreviations: EQ-5D-5L, European quality of life measure-5 domain-5 level; GCS, Glasgow coma scale; GOS, Glasgow outcome scale; IQR, interquartile range; SD, standard deviation; TBI, traumatic brain injury; VAS, visual analogue scale. score $(\mathrm{r}=0.83 ; p<0.001)$ ( - Fig. 1 ). The relationship of the EQ-5D-5L index scores and GCS and GOS are shown in ( -Figs. 2 a-b), respectively. The linear and nonlinear regression models were used to establish the relationship between the EQ-5D-5L index scores and other variables (-Figs. 3 a-f for the GCS and -Figs. 4 a-d).

Simple linear regression analyses were performed with the clinical variables; therefore, the GCS, surgery, pupillary light reflex and GOS were significant with candidate variables. The four candidate variables were included in the multiple regression model with the backward stepwise procedure. The final model comprised the GOS, surgery and pupillary light reflex variables for the multivariable analysis (-Table 3 ). Also, the multicollinearity of the variables was estimated among the candidate variables. The VIF of the GOS, surgery, and pupillary light reflex was $1.30,1.39$, and 1.44 , respectively, while the tolerance of the GOS, surgery, and pupillary light reflex was $0.766,0.719$, and 0.694 , respectively. For the predictive performance, the final model had a high adjusted $\mathrm{R}^{2}$ of 0.6971 and a low RMSE of 0.06701 . Alternatively, the polynomial regression model of

Table 2 Mean and median of EQ-5D-5L index scores according to clinical characteristics

\begin{tabular}{|c|c|c|c|}
\hline Factor & Mean (SD) & Median (IQR) & $p$ value $^{a}$ \\
\hline \multicolumn{4}{|l|}{ Age group-year } \\
\hline$<40$ & $0.91401(0.13087)$ & $\begin{array}{l}0.93200 \\
(0.075)\end{array}$ & 0.16 \\
\hline$\geq 40$ & $0.91734(0.08010)$ & $\begin{array}{l}0.92800 \\
(0.806)\end{array}$ & \\
\hline \multicolumn{4}{|l|}{ Gender } \\
\hline Male & $0.91658(0.09837)$ & $\begin{array}{l}0.93200 \\
(0.068)\end{array}$ & 0.60 \\
\hline Female & $0.91395(0.12671)$ & $\begin{array}{l}0.93200 \\
(0.077)\end{array}$ & \\
\hline \multicolumn{4}{|l|}{ Mechanism of injury } \\
\hline Road traffic injury & $0.93236(0.057195)$ & $\begin{array}{l}0.93200 \\
(0.068)\end{array}$ & 0.29 \\
\hline Nonroad traffic injury & $0.88013(0.170241)$ & $\begin{array}{l}0.93000 \\
(0.095)\end{array}$ & \\
\hline \multicolumn{4}{|l|}{ Loss of consciousness } \\
\hline No & $0.92638(0.08137)$ & $\begin{array}{l}0.93200 \\
(0.068)\end{array}$ & 0.26 \\
\hline Yes & $0.87554(0.174980)$ & $\begin{array}{l}0.92800 \\
(0.112)\end{array}$ & \\
\hline \multicolumn{4}{|l|}{ Amnesia } \\
\hline No & $0.92477(0.084231)$ & $\begin{array}{l}0.95330 \\
(0.068)\end{array}$ & 0.58 \\
\hline Yes & 0.86359 (0.194499) & $\begin{array}{l}0.93200 \\
(0.184)\end{array}$ & \\
\hline \multicolumn{4}{|l|}{ Vomiting } \\
\hline No & $0.91410(0.118629)$ & $\begin{array}{l}0.03200 \\
(0.068)\end{array}$ & 0.56 \\
\hline Yes & $0.92123(0.065496)$ & $\begin{array}{l}0.92800 \\
(0.082)\end{array}$ & \\
\hline
\end{tabular}


e104 Predicting the Health-related Quality of Life in Patients Following Traumatic Brain Injury Tunthanathip et al.

Table 2 (Continued)

\begin{tabular}{|c|c|c|c|}
\hline Factor & Mean (SD) & Median (IQR) & $p$ value $^{a}$ \\
\hline \multicolumn{4}{|l|}{ Age group-year } \\
\hline No & $0.93429(0.063533)$ & $\begin{array}{l}0.93200 \\
(0.068)\end{array}$ & 0.17 \\
\hline Yes & $0.90146(0.132928)$ & $\begin{array}{l}0.93200 \\
(0.088)\end{array}$ & \\
\hline \multicolumn{4}{|l|}{ Bleeding per ear/nose } \\
\hline No & $0.91441(0.111364)$ & $\begin{array}{l}0.93200 \\
(0.068)\end{array}$ & 0.70 \\
\hline Yes & 0.94671 (0.033099) & $\begin{array}{l}0.93200 \\
(0.040)\end{array}$ & \\
\hline \multicolumn{4}{|l|}{ Hypotension episode } \\
\hline No & 0.91865 (0.096839) & $\begin{array}{l}0.93200 \\
(0.068)\end{array}$ & 0.75 \\
\hline Yes & $0.72100(0.458357)$ & $\begin{array}{l}0.97100 \\
(0.808)\end{array}$ & \\
\hline \multicolumn{4}{|l|}{ Seizure } \\
\hline No & $0.91669(0.109280)$ & $\begin{array}{l}0.93200 \\
(0.068)\end{array}$ & 0.31 \\
\hline Yes & $0.84533(0.133960)$ & $\begin{array}{l}0.77000 \\
(-)\end{array}$ & \\
\hline \multicolumn{4}{|l|}{ GCS } \\
\hline $13-15$ & $0.93454(0.057956)$ & $\begin{array}{l}0.93200 \\
(0.068)\end{array}$ & $<0.001$ \\
\hline $9-12$ & $0.83371(0.123323)$ & $\begin{array}{l}0.88500 \\
(0.162)\end{array}$ & \\
\hline $3-8$ & $0.51257(0.249039)$ & $\begin{array}{l}0.51300 \\
(0.357)\end{array}$ & \\
\hline \multicolumn{4}{|l|}{ Pupillary light reflex } \\
\hline No react pupils & $0.61500(0.273565)$ & $\begin{array}{l}0.70550 \\
(0.467)\end{array}$ & $<0.001$ \\
\hline React pupils & $0.92522(0.085958)$ & $\begin{array}{l}0.93200 \\
(0.068)\end{array}$ & \\
\hline \multicolumn{4}{|l|}{ Surgery } \\
\hline No & $0.93153(0.081419)$ & $\begin{array}{l}0.93200 \\
(0.068)\end{array}$ & 0.008 \\
\hline Yes & $0.73913(0.199673)$ & $\begin{array}{l}0.79000 \\
(0.306)\end{array}$ & \\
\hline \multicolumn{4}{|l|}{ GOS } \\
\hline Vegetative state & $\begin{array}{l}0.288000 \\
(-)\end{array}$ & $\begin{array}{l}0.28800 \\
(-)\end{array}$ & $<0.001$ \\
\hline Severe disability & $0.36533(0.162032)$ & $\begin{array}{l}0.39100 \\
(-)\end{array}$ & \\
\hline Moderate disability & $0.62533(0.023029)$ & $\begin{array}{l}0.63100 \\
(-)\end{array}$ & \\
\hline Good recovery & $0.93251(0.059101)$ & $\begin{array}{l}0.93200 \\
(0.068)\end{array}$ & \\
\hline
\end{tabular}

Abbreviations: EQ-5D-5L, European quality of life measure-5 domain-5 level; GCS, Glasgow coma scale; GOS, Glasgow outcome scale. ${ }^{a} p$ value of Mann-Whitney $U$ test.

${ }^{\mathrm{b}} p$ value of one-way analysis of variance (ANOVA) test. 


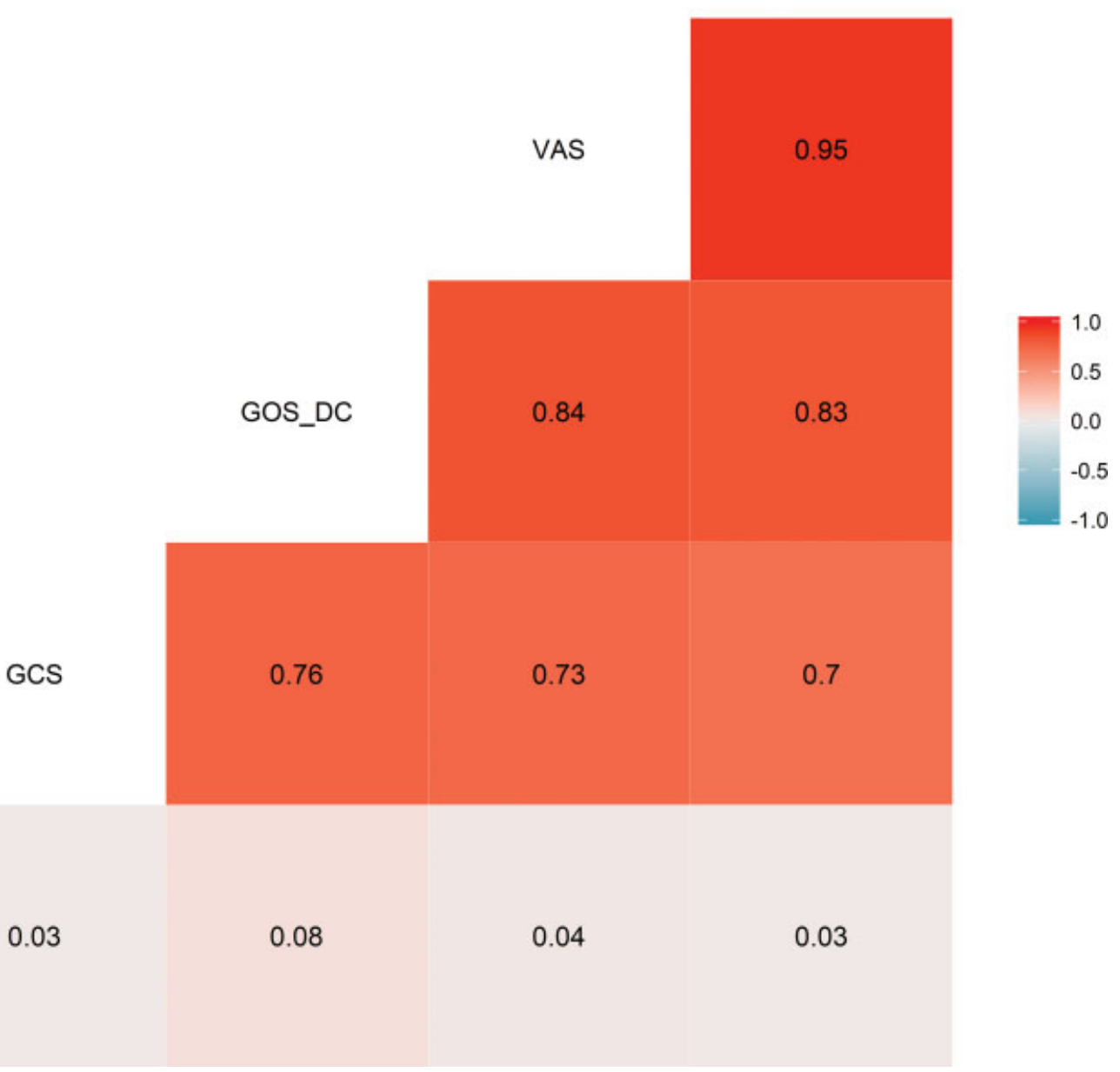

Fig. 1 Correlation of the clinical characteristics and European quality of life measure-5 domain-5 level (EQ-5D-5L) index scores.

the nonlinear approach had the highest adjusted $\mathrm{R}^{2}$ of 0.6843 and the lowest RMSE of 0.06748 . Moreover, the results of the HRQoL obtained by the VAS method were in concordance with the EQ-5D-5L questionnaire method (Supplementary Material; available online only).

\section{Discussion}

Poor functional outcomes among TBI patients have been observed in 0.6 to $24.3 \%$, while mortality ranged from 19.5 to $29.4 \%{ }^{35,36}$ Not only did mortality and morbidity have a direct impact on the individuals suffering from TBI, but longterm neurological sequelae were also socioeconomic burdens that should be of concern. ${ }^{10-12} \mathrm{HRQoL}$ is one of the health outcomes which was measured according to the patients' perspective according to the concept of holistic medicine. ${ }^{37}$

Although the EQ-5D-5L questionnaire is widely used to measure HRQoL, this tool is specifically built based on European measures. The socioeconomic and cultural issues vary in the eastern population which may affect the use of the tool. Pattanaphesaj et al conducted a survey of HRQoL in the Thai general population and developed a Thai value set for EQ-5D-5L which became the guidelines in Thailand. ${ }^{28,32}$ Therefore, we used this value set for HRQoL measurement in the present study. In the results, the GOS was a strong predictor associated with the HRQoL in which the concordance results were similar to those of prior reports. Kosty et al studied the relationship between the GOS-E with the HRQoL by using the standard gamble approach in 101 patients and demonstrated that there was a strong correlation between the GOS-E with the HRQoL $\left(R^{2}=0.637\right.$; $p<0.001) .{ }^{38}$ Also, the mean HRQoL of severe disability based on the GOS was less than the moderate disability and good recovery categories from Tsauo et al. ${ }^{39}$

From the literature review, a few studies mentioned HRQoL and the associated factors in TBI. Therefore, Ward et al developed a predictive model from the EQ-5D-5L index scores weighted on the GOS, age at injury, sex, comorbidity, and major extracranial injury from a systematic review and mapping approach. A linear relationship between the mean EQ-5D-5L values and GOS were described in the study. ${ }^{14,26}$ From the present study, the author developed a favorable 
A

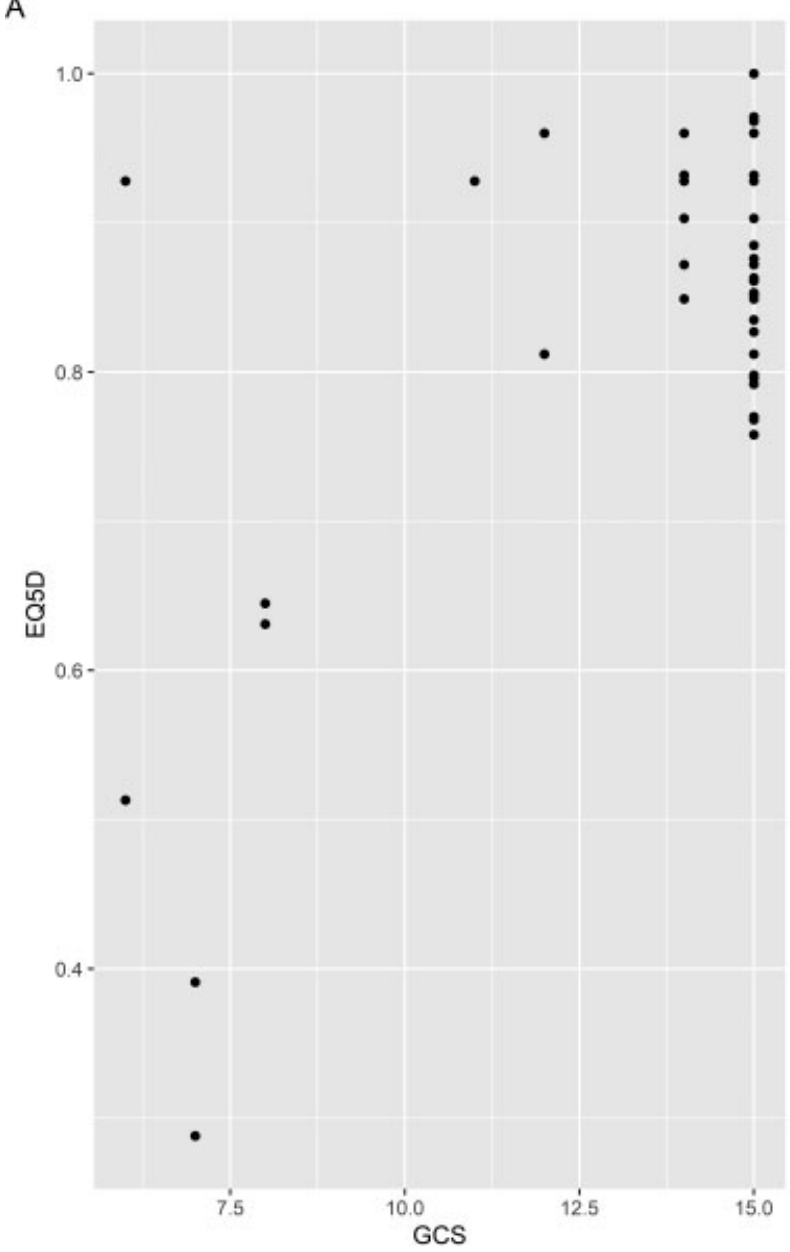

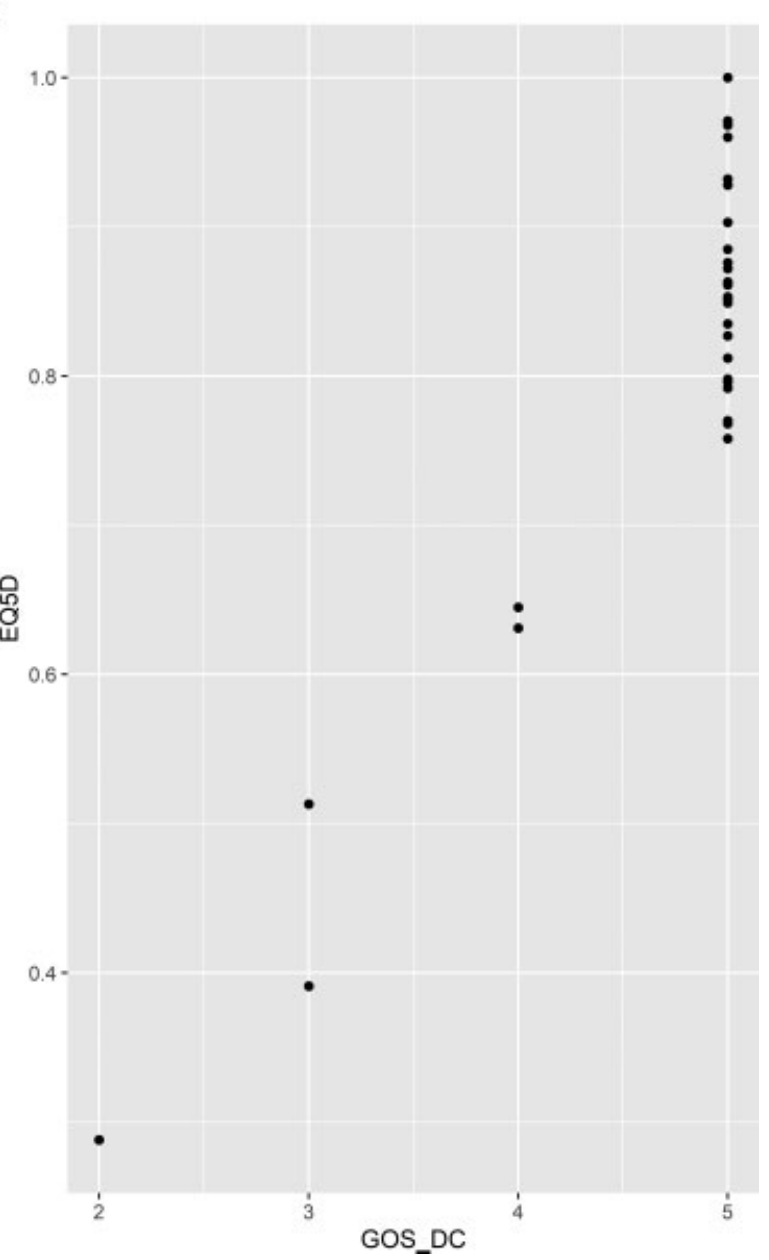

Fig. 2 Scatter plot of the European quality of life measure-5 domain-5 level (EQ-5D-5L) index scores with the significant variables. (a) Glasgow coma scale (GCS) score. (b) Glasgow outcome scale (GOS) score.

model predicting the EQ-5D-5L index scores based on the GOS, surgery, and pupillary light reflex.

The GCS was one of the predictors in the univariate analysis. Although the GCS is significantly correlated with the GOS $(r=0.076 ; p<0.001)$, the VIF and tolerance of the GCS variables in the multivariable analysis were not out of range, so there was no multicollinearity in the full model. However, the GCS had a low performance for prediction; hence, the GCS variable was finally removed during the selection of the model. This result may have occurred from an imbalance in the numbers of the GCS which were mainly 13 to 15 in the present cohort. Therefore, compared with previous studies, the present finding was in concordance with the literature. ${ }^{40,41}$ Kodliwadmath et al studied 82 TBI patients and found that there was a statistically significant positive correlation between the GCS on admission with the GOS documented on day $7(r=6.19)$ and the GOS listed on day $28(\mathrm{r}=5.77) .{ }^{41}$

Although linear regression has been used for predicting the HRQoL, ${ }^{40,42-44}$ the present study proposed alternative approaches for predicting the EQ-5D-5L index scores by a nonlinear model. To the author's knowledge, this was the first study that had revealed polynomial regression with acceptable performance to predict the EQ-5D-5L index scores using a single variable like the GOS.

The limitations of the present study were also acknowledged. First, an imbalance in the number of patients with moderate-to-severe TBI was detected in the current cohort. Moderate-to-severe TBI patients would need a longer time for recovery than the remaining group. Assessment of the outcome and HRQoL in the long-term follow-up may also demonstrate more informative results. Moreover, a metaanalysis or multicenter study should be conducted in the future to increase the number of the study population. Likewise, the present study's predictive models would need to be tested and improve their performance by external validation with unobserved data. ${ }^{45}$ Second, the observational study design resulted in a bias from the confounders. Although the multivariable analysis could control the confounding factors, nowadays the propensity score approach is an alternative way to resolve this problem for a nonrandomized controlled trial. ${ }^{46}$ Third, prior studies were concerned that the GOS might lead to a ceiling effect and the GOS-E was replaced for the assessment of the outcome. However, the 
A

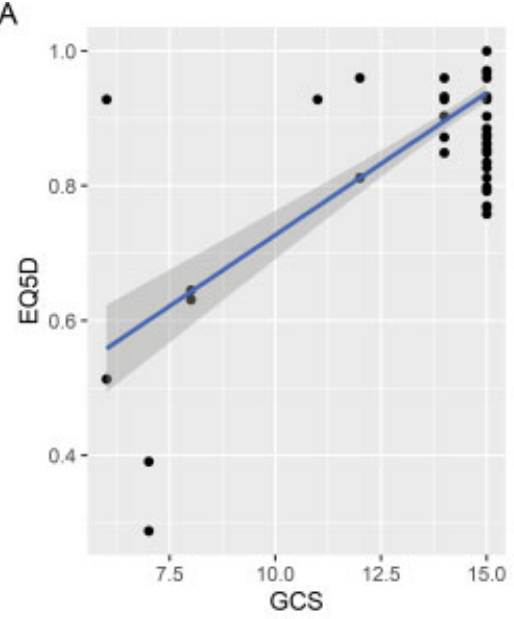

D

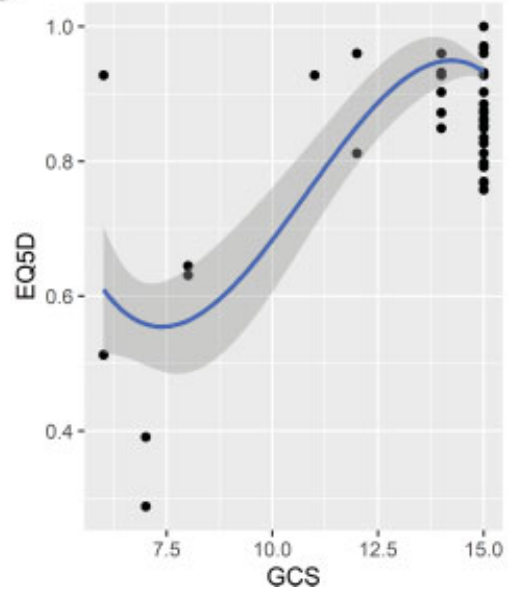

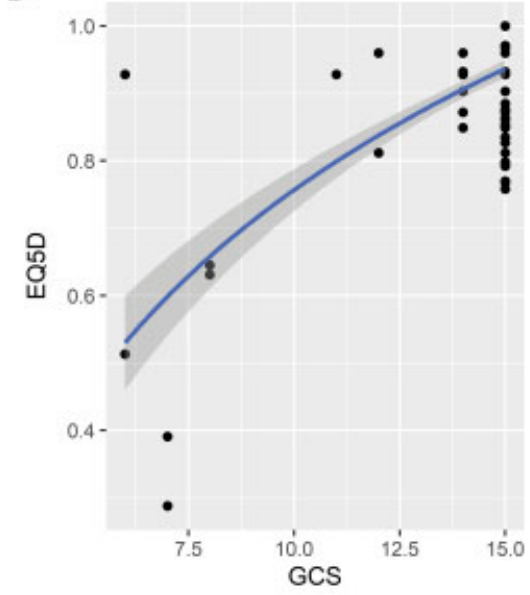

$E$

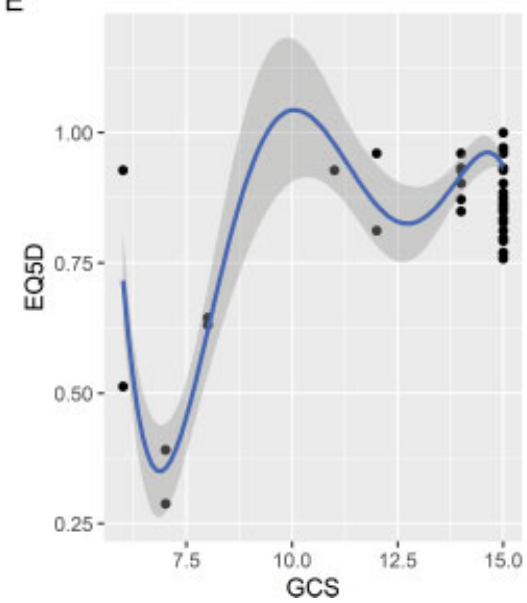

C

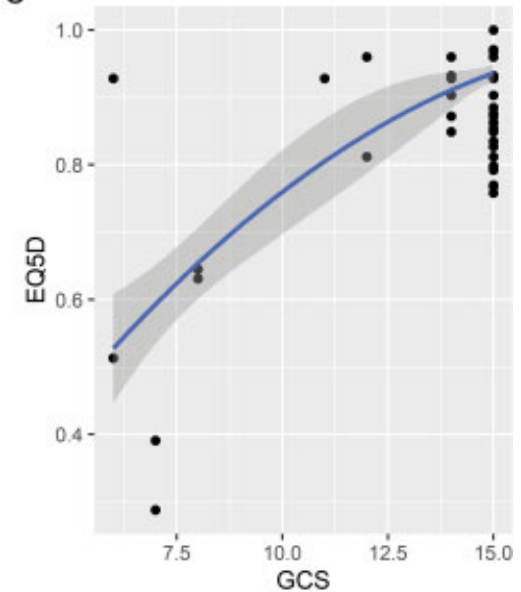

$\mathrm{F}$

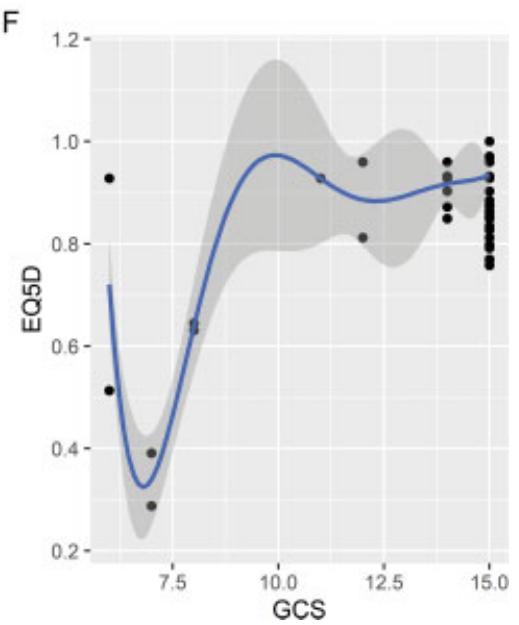

Fig. 3 Linear and nonlinear model fitting of the European quality of life measure-5 domain-5 level (EQ-5D-5L) index scores with the Glasgow coma scale score (GCS). (a) Linear regression, (b) log transformation, (c) cubic spline regression, (d) 3-order polynomial regression, (e) 5-order polynomial regression, and (f) 6-order polynomial regression.

sample size should be further enlarged for testing the hypothesis when using the eight-scale GOS-E.

Finally, the assessment of the GOS and HRQoL were estimated only before the participants were discharged from hospital. Prior studies had principally estimated the patients' outcome within 6 months. ${ }^{40}$ On the other hand, posttraumatic complications such as postconcussion syndrome were found within the first week to 3 months ${ }^{47,48}$ and affected the HRQoL. ${ }^{49}$ Hence, long-standing assessments of the outcome and the HRQoL should be conducted in the future for long-term results.

\section{Conclusions}

In summary, the current study revealed a positive relationship between physician-based outcome (GOS) and patientbased outcome (HRQoL). Moreover, both the linear and nonlinear regression models were acceptable approaches to predict the HRQoL of patients after TBI. There would be limitations to obtain the HRQoL from unconsciousness or intubated patients directly; therefore, this would be a challenge to use the predicted values for estimating HRQoL.
Financial Support and Sponsorship

Faculty of Medicine, Prince of Songkla University, HatYai, Songkhla, 90110, Thailand. (REC.61-116-10-1)

\section{Declarations}

All procedures performed in the study that involved studies involving human participants were in accordance with the ethical standards of the institutional and/or national research committee or both and with the 1964 Helsinki Declaration and its later amendments or comparable ethical standards (REC.61-116-10-1).

\section{Author Contributions}

TT and TO conceived the study and designed the method. TT, SS, SM, and SI supervised the conduct of the data collection. TT and TO undertook the recruitment of participating centers and patients and managed the data, including quality control. TT, PT provided statistical advice on the study design and analyzed the data. TT and TO drafted the manuscript, and all authors contributed substantially to its revision. TT takes responsibility for the paper as a whole. 
A

$1.00-$

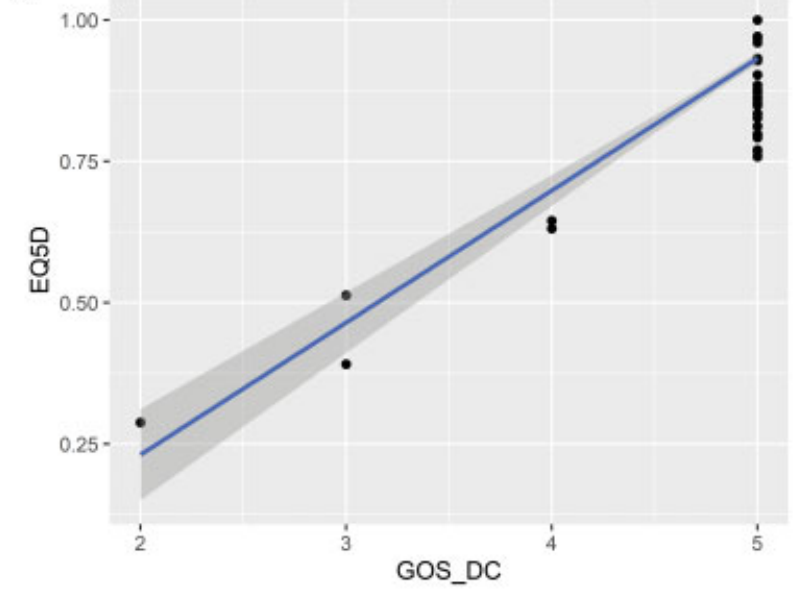

C

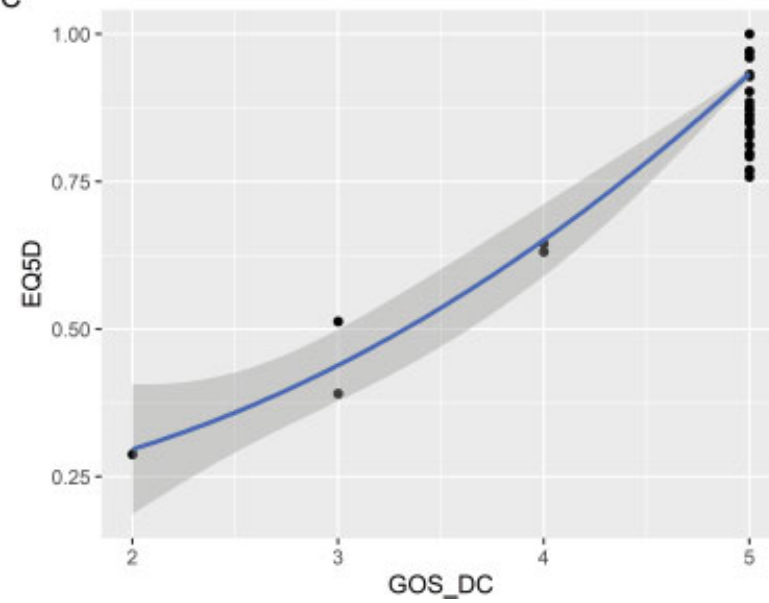

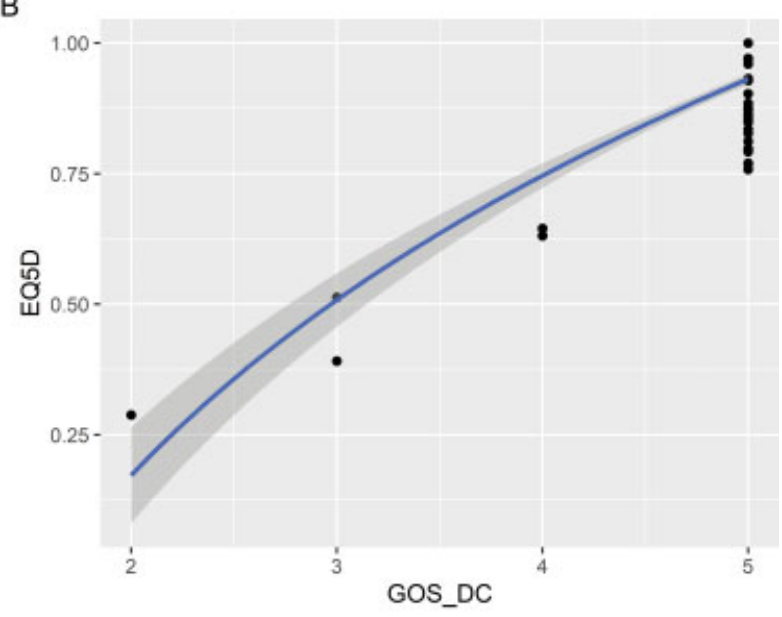

D

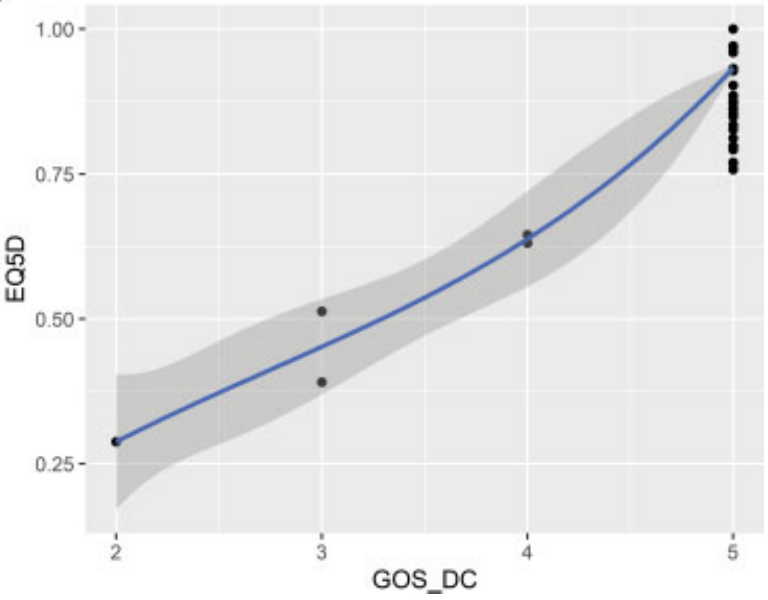

Fig. 4 Linear and nonlinear model fitting of the European quality of life measure-5 domain-5 level (EQ-5D-5L) index scores with the Glasgow outcome scale (GOS) score. (a) Linear regression, (b) log transformation, (c) polynomial regression, and (d) cubic spline regression.

Table 3 Linear and nonlinear fitting between EQ-5D-5L index value and various variables

\begin{tabular}{|c|c|c|c|c|}
\hline Factor & Coefficient & $p$ value & Adjusted R-squared & RMSE (prediction) \\
\hline \multicolumn{5}{|c|}{ Simple linear regression } \\
\hline $\begin{array}{l}\text { GCS } \\
\text { - intercept } 0.262\end{array}$ & 0.045 & $<0.001$ & 0.4770 & 0.08641 \\
\hline $\begin{array}{l}\text { Surgery } \\
\text { - intercept } 0.932\end{array}$ & -0.192 & $<0.001$ & 0.2928 & 0.11330 \\
\hline $\begin{array}{l}\text { Pupillary light reflex } \\
\text { - intercept } 0.615\end{array}$ & 0.310 & $<0.001$ & 0.1364 & 0.09326 \\
\hline $\begin{array}{l}\text { GOS } \\
\text { - intercept }-0.370\end{array}$ & 0.260 & $<0.001$ & 0.6790 & 0.07008 \\
\hline \multicolumn{5}{|c|}{ Multiple linear regression } \\
\hline Full model $^{a}$ & & & 0.6953 & 0.06741 \\
\hline Intercept & -0.302 & & & \\
\hline GOS & 0.230 & $<0.001$ & & \\
\hline Pupillary light reflex & 0.102 & 0.001 & & \\
\hline Surgery & -0.039 & 0.060 & & \\
\hline GCS & 0.009 & 0.852 & & \\
\hline Final model $^{\mathrm{b}}$ & & & 0.6971 & 0.06701 \\
\hline
\end{tabular}


Table 3 (Continued)

\begin{tabular}{|c|c|c|c|c|}
\hline Factor & Coefficient & $p$ value & Adjusted R-squared & RMSE (prediction) \\
\hline \multicolumn{5}{|c|}{ Simple linear regression } \\
\hline Intercept & -0.302 & & & \\
\hline GOS & & $<0.001$ & & \\
\hline Pupillary light reflex & 0.100 & 0.001 & & \\
\hline Surgery & -0.038 & 0.041 & & \\
\hline \multicolumn{5}{|c|}{ Nonlinear regression by GOS } \\
\hline Log transformation & & & 0.6574 & 0.07462 \\
\hline Intercept & -0.040131 & & & \\
\hline $\log (\mathrm{GOS})$ & 0.02788 & $<0.001$ & & \\
\hline Spline regression & & & 0.6824 & 0.06819 \\
\hline Intercept & 0.28800 & & & \\
\hline 1st knot & 0.18192 & 0.304 & & \\
\hline 2nd knot & 0.26671 & 0.068 & & \\
\hline 3rd knot & 0.64475 & $<0.001$ & & \\
\hline Polynomial & & & 0.6843 & 0.06748 \\
\hline Intercept & 0.9166 & & & \\
\hline 1st order & 1.00265 & $<0.001$ & & \\
\hline 2nd order & 0.10085 & $<0.001$ & & \\
\hline
\end{tabular}

Abbreviation: GCS, Glasgow coma scale; GOS, Glasgow outcome scale; IQR, interquartile range; RMSE, root mean square error; SD, standard deviation; VIF, variance inflation factors.

${ }^{a}$ VIF of GOS, pupillary light reflex, surgery, and GCS were $2.38,1.55,1.85$, and 3.84 , while tolerances of those were $0.419,0.643,0.538$, and 0.260 , respectively.

${ }^{b}$ VIF of GOS, pupillary light reflex, and surgery were $1.30,1.39$, and 1.44 , while tolerances of those were $0.766,0.719$, and 0.694 , respectively.

Conflicts of Interest

None declared.

\section{Acknowledgment}

The authors would like to offer their special thanks to Professor Nakornchai Phuenpathom for their advice regarding manuscript preparation.

\section{References}

1 The Centers for Disease Control and Prevention. CDC newsroom. Accessed December 1, 2020 at: https://www.cdc.gov/media/ releases/2018/p0904-tbi-guidelines.html

2 The Lancet. The burden of traumatic brain injury in children. Lancet 2018;391(10123):813

3 Suskauer SJ, Houtrow AJ. Invited commentary on "The Report to Congress on the Management of Traumatic Brain Injury in Children". Arch Phys Med Rehabil 2018;99(11):2389-2391

4 Lumba-Brown A, Yeates KO, Sarmiento K, et al. Centers for disease control and prevention guideline on the diagnosis and management of mild traumatic brain injury among children. JAMA Pediatr 2018;172(11):e182853

5 ThaiRoads Foundation and Thailand Accident Research Center (TARC), Asian Institute of Technology. Key facts on road safety situations in Thailand 2012-2013. Accessed December 1, 2020 at: http://www.roadsafetythai.org/edoc/doc_20181208173742.pdf

6 Tunthanathip T, Phuenpathom N. Impact of Road Traffic Injury to Pediatric Traumatic Brain Injury in Southern Thailand. J Neurosci Rural Pract 2017;8(04):601-608
7 Chaitanya K, Addanki A, Karambelkar R, Ranjan R. Traumatic brain injury in Indian children. Childs Nerv Syst 2018;34(06): 1119-1123

8 Fulkerson DH, White IK, Rees JM, et al. Analysis of long-term (median 10.5 years) outcomes in children presenting with traumatic brain injury and an initial Glasgow Coma Scale score of 3 or 4. J Neurosurg Pediatr 2015;16(04):410-419

9 The Centers for Disease Control and Prevention. Traumatic Brain Injury \& Concussion: Severe TBI. Accessed December 1, 2020 at: https://www.cdc.gov/traumaticbraininjury/severe.html

10 Kavosi Z, Jafari A, Hatam N, Enaami M. The economic burden of traumatic brain injury due to fatal traffic accidents in shahid rajaei trauma hospital, shiraz, iran. Arch Trauma Res 2015;4(01): e22594

11 National Institute for Health and Care Excellence. Guide to the Methods of Technology Appraisal 2013. Accessed December 1, 2020 at: https://www.nice.org.uk/process/pmg9/chapter/ foreword

12 Dijkers MP. Quality of life after traumatic brain injury: a review of research approaches and findings. Arch Phys Med Rehabil 2004; 85(04, Suppl 2):S21-S35

13 World Health Organization. WHOQOL: Measuring Quality of Life. Accessed December 1, 2020 at: https://www.who.int/healthinfo/ survey/whoqol-qualityoflife/en/

14 von Steinbuechel N, Covic A, Polinder S, et al. Assessment of Health-Related Quality of Life after TBI: Comparison of a DiseaseSpecific (QOLIBRI) with a Generic (SF-36) Instrument. Behav Neurol 2016;2016:7928014

15 Born K, Amsler F, Gross T. Prospective evaluation of the Quality of Life after Brain Injury (QOLIBRI) score: minor differences in 
patients with major versus no or mild traumatic brain injury at one-year follow up. Health Qual Life Outcomes 2018;16(01):136

16 Carlozzi NE, Kallen MA, Hanks R, et al. The TBI-CareQOL Measurement System: Development and Preliminary Validation of HealthRelated Quality of Life Measures for Caregivers of Civilians and Service Members/Veterans With Traumatic Brain Injury. Arch Phys Med Rehabil 2019;100(4S):S1-S12

17 Steadman-Pare D, Colantonio A, Ratcliff G, Chase S, Vernich L. Factors associated with perceived quality of life many years after traumatic brain injury. J Head Trauma Rehabil 2001;16(04): 330-342

18 Johnson JA, Luo N, Shaw JW, Kind P, Coons SJ. Valuations of EQ-5D health states: are the United States and United Kingdom different? Med Care 2005;43(03):221-228

19 Yang Z, Busschbach J, Liu G, Luo N. EQ-5D-5L norms for the urban Chinese population in China. Health Qual Life Outcomes 2018;16 (01):210

20 Golicki D, Niewada M. EQ-5D-5L Polish population norms. Arch Med Sci 2017;13(01):191-200

21 Jakola AS, Unsgård G, Solheim O. Quality of life in patients with intracranial gliomas: the impact of modern image-guided surgery. J Neurosurg 2011;114(Suppl 6):1622-1630

22 Jansson KA, Németh G, Granath F, Jönsson B, Blomqvist P. Healthrelated quality of life (EQ-5D) before and one year after surgery for lumbar spinal stenosis. J Bone Joint Surg Br 2009;91(02): 210-216

23 Tajima R, Kondo M, Kai H, et al. Measurement of health-related quality of life in patients with chronic kidney disease in Japan with EuroQol (EQ-5D). Clin Exp Nephrol 2010;14(04):340-348

24 Parik PC, Patel VJ. Health-related quality of life of patients with type 2 diabetes mellitus at a tertiary care hospital in India using EQ 5D 5L. Indian J Endocrinol Metab 2019;23(04):407-411

25 Voormolen DC, Cnossen MC, Polinder S, et al. Prevalence of postconcussion-like symptoms in the general population in Italy, The Netherlands and the United Kingdom. Brain Inj 2019;33(08): 1078-1086

26 Ward Fuller G, Hernandez M, Pallot D, Lecky F, Stevenson M, Gabbe B. Health state preference weights for the Glasgow outcome scale following traumatic brain injury: a systematic review and mapping study. Value Health 2017;20(01):141-151

27 EuroQol Research Foundation. EQ-5D-5L. Accessed December 1, 2020 at: https://euroqol.org/eq-5d-instruments/eq-5d-5l-about/

28 Pattanaphesaj J. Health-related quality of life measure (EQ-5D$5 \mathrm{~L})$ : measurement property testing and its preference-based score in Thai population [doctoral dissertation]. Mahidol University 2014

29 Perry EC III, Ahmed HM, Origitano TC. Neurotraumatology. Handb Clin Neurol 2014;121:1751-1772

30 Maas AI, Marmarou A, Murray GD, Teasdale SG, Steyerberg EW. Prognosis and clinical trial design in traumatic brain injury: the IMPACT study. J Neurotrauma 2007;24(02):232-238

31 Edwards P, Arango M, Balica L, et al; CRASH trial collaborators. Final results of MRC CRASH, a randomised placebo-controlled trial of intravenous corticosteroid in adults with head injuryoutcomes at 6 months. Lancet 2005;365(9475):1957-1959

32 Pattanaphesaj J, Thavorncharoensap M, Ramos-Goñi JM, Tongsiri S, Ingsrisawang L, Teerawattananon Y. The EQ-5D-5L valuation study in Thailand. Expert Rev Pharmacoecon Outcomes Res 2018; 18(05):551-558

$33 \mathrm{Kim} \mathrm{JH}$. Multicollinearity and misleading statistical results. Korean J Anesthesiol 2019;72(06):558-569

34 Yoo W, Mayberry R, Bae S, et al; A study of effects of multicollinearity in the multivariable analysis. Int J Appl Sci Technol 2014;4(5):9-19

35 Jiang JY, Gao GY, Li WP, Yu MK, Zhu C. Early indicators of prognosis in 846 cases of severe traumatic brain injury. J Neurotrauma 2002;19(07):869-874

36 Perel P, Arango M, Clayton T, et al; MRC CRASH Trial Collaborators. Predicting outcome after traumatic brain injury: practical prognostic models based on large cohort of international patients. BM] 2008;336(7641):425-429

37 Owolabi MO. Health-related quality of life (HRQOL) measures: there are still many unanswered questions about human life. ScientificWorldJournal 2008;8:357-363

38 Kosty J, Macyszyn L, Lai K, McCroskery J, Park HR, Stein SC. Relating quality of life to Glasgow outcome scale health states. J Neurotrauma 2012;29(07):1322-1327

39 Tsauo JY, Hwang JS, Chiu WT, Hung CC, Wang JD. Estimation of expected utility gained from the helmet law in Taiwan by qualityadjusted survival time. Accid Anal Prev 1999;31(03):253-263

40 Balestreri M, Czosnyka M, Chatfield DA, et al. Predictive value of Glasgow Coma Scale after brain trauma: change in trend over the past ten years. J Neurol Neurosurg Psychiatry 2004;75(01):161-162

41 Kodliwadmath HB, Koppad SN, Desai M, et al. Correlation of Glasgow Outcome Score to Glasgow Coma Score Assessed at Admission. Accessed December 1, 2020 at: https://www. ijsurgery.com/index.php/isj/article/view/131

42 Verdugo MA, Fernández M, Gómez LE, Amor AM, Aza A. Predictive factors of quality of life in acquired brain injury. Int J Clin Health Psychol 2019;19(03):189-197

43 Weber KT, Guimarães VA, Pontes Neto OM, Leite JP, Takayanagui $\mathrm{OM}$, Santos-Pontelli TE. Predictors of quality of life after moderate to severe traumatic brain injury. Arq Neuropsiquiatr 2016;74(05): 409-415

44 Yuan F, Ding J, Chen $\mathrm{H}$, et al. Predicting outcomes after traumatic brain injury: the development and validation of prognostic models based on admission characteristics. J Trauma Acute Care Surg 2012;73(01):137-145

45 Tunthanathip T, Sae-Heng S, Oearsakul T, et al. Machine learning applications for the prediction of surgical site infection in neurological operations. Neurosurg Focus 2019;47(02):E7

46 Tunthanathip T, Sangkhathat S. Temozolomide for patients with wild-type isocitrate dehydrogenase (IDH) 1 glioblastoma using propensity score matching. Clin Neurol Neurosurg 2020; 191:105712

47 Maas AI, Stocchetti N, Bullock R. Moderate and severe traumatic brain injury in adults. Lancet Neurol 2008;7(08):728-741

48 Mayo clinic. Post-concussion syndrome. Accessed December 1, 2020 at: https://www.mayoclinic.org/diseases-conditions/postconcussion-syndrome/symptoms-causes/syc-20353352

49 Karzmark P, Hall K, Englander J. Late-onset post-concussion symptoms after mild brain injury: the role of premorbid, injury-related, environmental, and personality factors. Brain Inj 1995;9(01):21-26 